Military Technical College, Kobry El-Kobbah, Cairo, Egypt

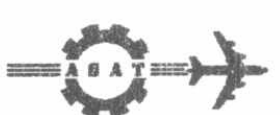

$9^{\text {th }}$ International Conference

On Aerospace Sciences \& Aviation Technology

\title{
THEORY AND EXPERIMENT OF DISK FLEXIBILITY INFLUENCES ON TURBOROTOR VIBRATIONS
}

\author{
GAFFER ${ }^{*}$ H. I. and ELBEHEIRY*E. M.
}

\section{ABSTRACT}

This paper investigates the vibration problems associated with the attachment of flexible disks to high speed, flexible rotors. A semi-analytical finite element method has been employed to model two flexible disks attached to a flexible rotor supported by three ball bearings. A two-nodes beam element of 8-DOF is used to model the flexural vibrations of the flexible rotor while a four-node (arranged on two perpendicular diameters) annular circular plate element of 8-DOF is used to model the transverse vibrations of the flexible disks. The system natural frequencies and critical speeds are computed in a speed rang up to a 5000 RPM. An experimental test rig has been employed to validate the theoretical findings. An acceptable matching has been found between the experimental and the simulation results. Most importantly, the results reveal that the rotor natural frequencies and critical speeds are marginally influenced by the disk flexibility. The main contribution of this work is that the inclusion of disk flexibility in the modeling process effectively reduces the modeling error, which seems to be crucial for some applications.

\section{KEY WORDS}

Rotors, disks, flexibility, whirling, finite element, experiment.

\section{INTRODUCTION}

Research trend in rotordynamic analyses is now going so far beyond the topic of unbalanced operations of flexible-rotor/rigid-disk systems. Rotor vibrations due to unbalance, coming from either inhornogeneous rotor material distribution or imperfect rigid disk symmetry around the axis of rotation, have not become the only important issue. Other important problems have attracted the researchers owing to increasing demand in industry to very fast rotors of light weights and reliable operations. In general, as the rotating system becomes lighter and more flexible with higher operating speed for higher productivity and economical design, the flexibleshaft/rigid-disk modeling becomes not sufficient to accurately predict the vibration characteristics of the system. Flexibility of circular thick or thin disks by itself is an important practical problem that attracted the attention of a large number of researchers in both mechanical and structure engineering fields.

\footnotetext{
* Lecturer, Dept. of Production Engineering and Mechanical Design, Faculty of Engineering, Menoufia University, Shebin ElKom, Egypt.
} 
Among the currently undertaken research topics around the world in the rotordynamics field are: active magnetic bearings, active control of industrial turborotors, disk flexibility effects on rotor natural frequencies and critical speeds, rubbing phenomena in journal bearing due to nonlinear effects and unconsidered sources of excitation like random seismological shakes, active journal bearing and active squeezed film dampers, development of modeling and analysis software to fasten and deepen the task of the rotordynamic analyst, etc. Recently, ElBeheiry published two papers $[1,2]$ concerning the possibility of controlling random vibrations in turborotors in an attempt to reduce the rubbing phenomena in journal bearings due to light or moderate seismic (random) excitations. A covariance control strategy was suggested and found to be effective on this issue.

There are so many applications in industry in which the flexibility of disks attached to rotor shafts might be of noticeable influences on the system natural frequencies and critical speeds. Examples of these are aircraft engines, turbomachinery rotors, circular saws, geared transmission and computer disk drives, etc. In the early work of Chivens and Nelson [3] the authors reported that the disk flexibility is of marginal effect on the natural frequencies but of negligible effect on the rotor critical speeds. Actually, this result was confusing to the rotordynamics community, especially, the authors were used symmetrical bearings, which might vanish the disk flexibility effect. This work has been followed by the paper of Wilgen and Schlack [4] in which the authors used the Lyapunov method to clarify some important issues. In particular, they showed that the disk flexibility could be significant at influencing the critical speeds as long as the ratio of disk mass to rotor mass is greater than $1 / 32$. Moreover, their investigations categorized the disk influence as maximum when it is attached in the vicinity of an end bearing. Eight years later, Shahab and Thomas [5] conducted the same research topic but for multiple flexible, thick disks mechanized to flexible, solid or hollow rotors by using a three-dimensional thick finite element specifically developed for studying their problem. They showed that thicker disks might have higher influence on the rotor modes rather than thinner ones. Vance [6] in his book reported that there are some effects of the disk flexibility on the computed and measured natural frequencies.

A very significant contribution was made by Sakata et al. [7] in the investigation of flexible-rotor/flexible-bladed-disk system subjected to a gyroscopic moment in order to simulate the aircraft turn. They used the annular disk element developed by Kirkhope and Wilson $[8,9]$ to obtain the disk mass and stiffness matrices, and found good agreement between their theoretical and experimental results. Flowers and his co-authors [10-12] confined themselves to the development of analytical and computational methods for studying the problem of flexible rotor/flexible disk system. The transfer matrix method [10] was found to be effective in providing computational results close by the analytical ones. Some other analytical methods can be found in references [13-17]. A semi-analytical conical finite element as developed by Ramesh and Ganesan [18], was employed by Kumar et al. [19] to predict the same problem. The advantages of this element over the other ones are due to its capability of modeling the flexibility of the rotor, the disks and the bearings. The authors compared their findings with those of Shahab et al. [5] and reported good agreement. Recently, Fung and Hsu [20] contributed to the subject by studying the eddy current brakes as one of the important applications that encounters the problem under investigation 
here. They used the assumed mode method as one of the substructure synthesis techniques. They showed that there is a chance to exploit the existence of the eddycurrent brake system in reducing the rotor vibrations.

In this paper, a semi-analytical finite element model has been used to study a flexible rotor supported by three ball bearings and carrying two flexible disks mounted close by the bearings. A two-nodes beam element of 8-DOF is used to model the flexural vibrations of the flexible rotor while a four-node annular circular plate element of 8 DOF is used to model the transverse vibrations of the flexible disks. Fixed and moving axis systems are coordinated together in order to obtain consistent finite element formulation for the overall assembled system. The aim is to identify the modeling error due to including or not including the disk flexibility in the dynamic model as compared to measured values by an experimental test rig.

\section{MODELING}

\subsection{Rotor Modeling}

The schematic diagram of the whirl apparatus that is used to perform this study is shown in Fig. 1. This apparatus allows the study of rotors having relatively small diameters and lengths. It comprises a driving DC motor of varying speed up to 6000 RPM and can be mechanized to the rotor under investigation through a Hook's joint. The apparatus also comprises three ball bearings for supporting the rotor one of them, which is the big one is installed at the inner diameter of a nonrotating housing located near by the Hook's joint. This (left) bearing supports the rotor through a rotating sleeve mounted at the inner diameter of the bearing inner race. The rotor and the sleeve rigidly connect through a stud. The other two bearings are fixed to a rotating sleeve at their inner race and the sleeve compounds with the rotor by the effect of a nut. The bearing characteristics were computed on the basis of an empirical formula as in the book of Harris [22].

The axis systems are arranged as shown in Fig. 2 such that: $\mathrm{O}-\mathrm{XYZ}$ is a fixed reference frame. The origin of the $\mathrm{O}^{\prime}-\mathrm{X}^{\prime} \mathrm{Y}^{\prime} \mathrm{Z}^{\prime}$ axis system coincides with the undeformed rotor centerline such that $Z^{\prime}$ coincides with the bearing centerlines. The $O^{\prime \prime}-X^{\prime \prime} Y^{\prime \prime} Z^{\prime \prime}$ axis system is a moving frame that accompanies the rotor whirl motion. The aim of this arrangement is to get the stiffness and mass matrices of both the rotor and the disks w.r.t. the axis system $O^{\prime \prime}-X^{\prime \prime} Y^{\prime \prime} Z^{\prime \prime}$ so that assembling difficulties of rotor and disk elements can be significantly avoided. According to Timoshenko beam theory, the rotor beam element [7] consists of two nodes at each one there are four displacements: one in the vertical direction, one in the horizontal direction, and the rotation around each one. The discretization process is schematically shown in Fig. 3. The components of the displacement of the beam element in the $X "$ and $Y "$ directions are expressed as follows:

$$
\mathrm{u}_{\mathrm{s}}(\mathrm{z})=\left\{\mathrm{S}_{\mathrm{s}}\right\}^{\mathrm{T}}[\mathrm{R}]\left\{\mathrm{u}_{\mathrm{s}}\right\}, \quad v_{s}(z)=\left\{S_{s}\right\}^{T}[R]\left\{v_{s}\right\}
$$

where $\left\{u_{s}\right\}$ and $\left\{v_{s}\right\}$ represent the nodal displacement vectors of a beam element, which are given by 


$$
\begin{array}{cl}
\left\{u_{s}\right\}=\left\{\begin{array}{llll}
u_{s 1} & \theta_{s x 1} & u_{s 2} & \theta_{s x 2}
\end{array}\right\}^{T}, & \left\{v_{s}\right\}=\left\{\begin{array}{llll}
v_{s 1} & \theta_{s y \mathrm{i}} & v_{s 2} & \theta_{s y 2}
\end{array}\right\}^{T} \\
\left\{S_{s}\right\}=\left\{\begin{array}{llllll}
1 & z & z^{2} & z^{3}
\end{array}\right\}^{T}, & {[R]=\left[\begin{array}{cccc}
1 & 0 & 0 & 0 \\
0 & 1 & 0 & 0 \\
1 & l & l^{2} & l^{3} \\
0 & 1 & 2 l & 3 l^{2}
\end{array}\right]^{-1}}
\end{array}
$$

where $\theta_{s x}$ and $\theta_{s y}$ are the deflection angles of the shaft in the ' ${ }^{\prime} ' Z$ ' and $\mathrm{X}^{\prime} \mathrm{Z}$ ' pianes, respectively. $u_{s}$ and $v_{s}$ are the displacement in $\mathrm{X}$ and $\mathrm{Y}$ directions respectively. $[R]$ is a transformation matrix. $\left\{S_{s}\right\}$ is a transformation vector. The kinetic energy of the rotor beam element is given by

$$
\begin{aligned}
T_{s} & =0.5 \rho_{s} \int_{V} \mathbf{v}_{s}^{T} \mathbf{v}_{s} d V \\
& =0.5\left\{\dot{u}_{s}\right\}^{T}\left[M_{s}\right]\left\{\dot{u}_{s}\right\}+0.5\left\{\dot{v}_{s}\right\}^{T}\left[M_{s}\right]\left\{\dot{v}_{s}\right\}+\Omega \dot{\theta}_{s x} \theta_{s y} I_{s p}+0.5 \dot{\theta}^{2}{ }_{s y} I_{s x}+0.5 \dot{\theta}^{2}{ }_{s x} I_{s y}
\end{aligned}
$$

where $\mathrm{v}_{s}$ is the vector velocity of the rotor center point, $\Omega$ is the rotor rotational speed, $\left[M_{s}\right]$ is the rotor element mass matrix in one plane of motion, $I_{s p}$ polar moment of inertia of the rotor element, and $l_{s x}, l_{s y}$ are the element moment of inertia about the axis $X$ and $Y$, respectively, $\rho_{s}$ is the density of shaft material. Applying Lagrange's equation to Eq. (4) the results carl be arranged in the following inertia and gyroscopic matrices of the element:

$$
\left[\begin{array}{cc}
{\left[M_{s}\right]} & 0 \\
0 & {\left[M_{s}\right]}
\end{array}\right]\left\{\begin{array}{l}
\ddot{u}_{s} \\
\ddot{v}_{s}
\end{array}\right\}+\left[\begin{array}{cc}
I_{s y} & 0 \\
0 & I_{s x}
\end{array}\right]\left\{\begin{array}{l}
\ddot{\theta}_{s x} \\
\ddot{\theta}_{s y}
\end{array}\right\}+\Omega\left[\begin{array}{cc}
0 & -I_{s p} \\
+I_{s p} & 0
\end{array}\right]\left\{\begin{array}{l}
\dot{\theta}_{s x} \\
\dot{\theta}_{s y}
\end{array}\right\}
$$

The strain energy of the beam elemert is given by

$$
U_{s}=0.5 \int E_{s} I_{s}\left[\left(\frac{\partial u_{s}}{\partial z^{2}}\right)^{2}+\left(\frac{\partial v_{s}}{\partial z^{2}}\right)^{2}\right] d z=0.5\left\{\dot{u}_{s}\right\}^{T}\left[K_{s}\right]\left\{\dot{u}_{s}\right\}+0.5\left\{\dot{v}_{s}\right\}^{T}\left[K_{s}\right]\left\{\dot{v}_{s}\right\}
$$

where $\left[K_{s}\right]$ is the rotor element stiffness matrix in one plane of motion, $E_{s}$ is the rotor modulus of elasticity, and $I_{s}$ is the shaft area moment of inertia. Applying Lagrange's equation to Eq. (4) provides the elastic element forces as follows:

$$
\left[\begin{array}{cc}
{\left[K_{s}\right]} & 0 \\
0 & {\left[K_{s}\right]}
\end{array}\right]\left\{\begin{array}{l}
u_{s} \\
v_{s}
\end{array}\right\}
$$

All the parameters and matrices that appeared in the last for equations are given in Appendix A. The detailed description of the rotor dimensions and its other properties 
are given in Table 1. The total number of DOF that describes the rotor bending vibration is 96 .

\subsection{Disk Modeling}

An annular plate element is used to describe the transverse vibration of the two disks as developed by Kirkhope and Wilson $[8,9]$. Each disk is discretized into four annular elements and each element has four nodal points arranged along two perpendicular diameters. Two transverse motions at each diameter in addition to two redial rotations are considered as shown in Fig. 2. Thus a total of 8-DOF describes the transverse vibration of each annular element and a total of 20-DOF describes the transverse vibration of each disk. Consequently, 40-DOF are used to describe the vibration of the two flexible disks. The kinetic energy of the annular element is given by:

$$
\begin{aligned}
T_{D}= & 0.5 \rho_{D} \int_{0}^{2 \pi r_{1}} \int_{r_{D}}^{T} \mathbf{v}_{D} d r d \xi \\
= & 0.5\left\{\dot{w}_{D x}\right\}^{T}\left[M_{D}\right]\left\{\dot{w}_{D x}\right\}+0.5\left\{\dot{w}_{D y}\right\}^{T}\left[M_{D}\right]\left\{\dot{w}_{D y}\right\}+\Omega\left\{\dot{w}_{D x}\right\}^{T}\left[M_{D}\right]\left\{w_{D x}\right\} \\
& -\Omega\left\{\dot{w}_{D y}\right\}^{T}\left[M_{D}\right]\left\{w_{D y}\right\}+0.5 \Omega^{2}\left\{w_{D x}\right\}^{T}\left[M_{D}\right]\left\{w_{D x}\right\}+0.5 \Omega^{2}\left\{w_{D y}\right\}^{T}\left[M_{D}\right]\left\{w_{D y}\right\} \\
& \Omega \dot{\theta}_{s x} \theta_{s y} I_{D p}+0.5 \dot{\theta}^{2}{ }_{s y} I_{D x}+0.5 \dot{\theta}^{2}{ }_{s x} I_{D y}+0.5 m_{D} \dot{v}^{2}{ }_{s D}
\end{aligned}
$$

where $\mathbf{v}_{D}$ is the transverse vector velocity of an arbitrary point $\mathrm{P}$ on the disk as shown in Fig. 2, $\left[M_{D}\right]$ is the disk element mass matrix, $I_{D p}$ polar moment of inertia of the disk element, and $I_{D x}, I_{D y}$ are the disk element moment of inertia about the axes $X$ and $Y$, respectively, $\rho_{D}$ is the density of disk material. The displacement of an arbitrary point $P$ on the disk is defined as follows:

$$
\begin{aligned}
& w_{D}(r)=\left\{S_{D}\right\}^{T}\left[B_{D}\right]\left\{w_{D x}\right\} \cos (\Omega t+\xi)+\left\{S_{D}\right\}^{T}\left[B_{D}\right]\left\{w_{D y}\right\} \sin (\Omega t+\xi), \\
& \left\{w_{D x}\right\}=\left\{\begin{array}{lllllll}
w_{D x 1} & \theta_{D x 1} & w_{D x 2} & \theta_{D x 2}
\end{array}\right\}^{T}, \quad\left\{w_{D y}\right\}=\left\{\begin{array}{llll}
w_{D y 1} & \theta_{D y 1} & w_{D y 2} & \theta_{D y 2}
\end{array}\right\}^{T}
\end{aligned}
$$

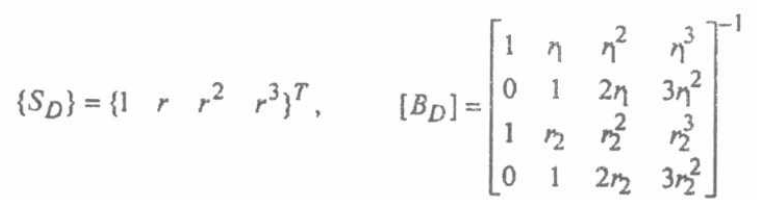

The application of Lagrange's equation to Eq. (8) yields the following inertia and gyroscopic matrices: 


$$
\left[\begin{array}{cc}
{\left[M_{D}\right]} & 0 \\
0 & {\left[M_{D}\right]}
\end{array}\right]\left\{\begin{array}{l}
\ddot{w}_{D x} \\
\ddot{w}_{D y}
\end{array}\right\}+\left[\begin{array}{cccc}
m_{D} & 0 & 0 & 0 \\
0 & I_{D x} & 0 & 0 \\
0 & 0 & m_{D} & 0 \\
0 & 0 & 0 & I_{D y}
\end{array}\right]\left\{\begin{array}{c}
\ddot{u}_{s D} \\
\ddot{\theta}_{s x D} \\
\ddot{v}_{s D} \\
\ddot{\theta}_{s y D}
\end{array}\right\}+\Omega\left[\begin{array}{cc}
0 & -I_{D p} \\
+I_{D p} & 0
\end{array}\right]\left\{\begin{array}{l}
\dot{\theta}_{s x D} \\
\dot{\theta}_{s y D}
\end{array}\right\}
$$

where the subscript " $D$ " denotes rotor node to which the disk is attached. The strain energy of the annular disk element is given by:

$$
\begin{aligned}
U_{D} & =0.5 \rho_{D} \int_{0}^{2 \pi r_{2}} \int_{r_{1}}\left\{\varepsilon_{D}\right\}^{T}\left[D_{D}\right\}\left\{\varepsilon_{D}\right\} h_{D}(r) r d r d \xi \\
& =0.5\left\{w_{D x}\right\}^{T}\left[K_{D}\right]\left\{w_{D x}\right\}+0.5\left\{w_{D y}\right\}^{T}\left[K_{D}\right]\left\{w_{D y}\right\}
\end{aligned}
$$

$h_{D}(r)$ is the disk thickness as a function of radius and $\left[K_{D}\right]$ is the disk element stiffness matrix in one plane of motion, $\left\{\varepsilon_{D}\right\}$ is the strain vector. The application of Lagrange's equation to Eq. (13) yields the disk elastic force in matrix form:

$$
\left[\begin{array}{cc}
{\left[K_{D}\right]} & 0 \\
0 & {\left[K_{D}\right]}
\end{array}\right]\left\{\begin{array}{l}
w_{D x} \\
w_{D y}
\end{array}\right\}
$$

\subsection{Equations of Motion}

Now, by the aid of Eqs. (5), (7), (12) and (14) the assembled 136 second-order ordinary differential equation that describe the coupled dynamics of the flexiblerotor/two-flexible-disks system can be arranged in the following matrix form:

$$
[M]\{\ddot{X}\}+\Omega[G]\{\dot{X}\}+[K]\{X\}=\left\{F_{u}\right\}
$$

The system of Eq. (15) is a conservative gyroscopic system where damping in ball bearing is not considered

\section{EXPERIMENTATION}

A photograph of the experimental test rig used to justify the theoretical results is shown in Fig. 4 and schematically shown in Fig. 5. After calibrating the instruments used in the measurement process, insurance of the proper isolation of the test rig from undesired sources of excitation is established. The measurement procedure includes B\&K impact hammer type 8202 with a force transducer type 8200 built into the tip to register the force input used to excite the system modes, a tap with the hammer imparts a pulse with a broadband frequency range to the system. This will excite all the modes of vibration. The signal from the force transducer is routed via a preamplifier to one channel of the Dual Channel Signal Analyzer model 2034. A piezoelectric accelerometer type 4370 is mounted on a measuring point that is chosen to be on the top of the left bearing in and positioned in the vertical direction. The accelerometer is connected to B\&K amplifier type 2635 and the amplifier is 
connected to the other channel of the Dual Channel Signal Analyzer as shown in Fig. 5. The machine set used is consisting of variable speed motor that drives the rotor under investigation. The operating speed of the rotor was calibrated by the use of two techniques: (1) the mechanical tachometer, and (2) the strobelight of the IRD microprocessor analyzer. An IEE interface between the dual channel signal analyzer and the computer is used to print out the frequency spectrum of the system at each experiment.

\section{RESULTS AND DISCUSSIONS}

Samples of measured frequency spectra are shown in Fig. 6. A MATLAB code has been developed for the computational procedure of the finite element method. In a speed range of 0 RPM to 5000 RPM with step 1000 RPM, the system natural frequencies are computed, and the theoretical versus experimental Campbell diagram are plotted in Fig. 7 for the first two forward and two backward modes. This diagram reveals that acceptable compatibility between the theoretical and the experimental measurement is achieved. Also, In Fig. 7, the first predicted critical speed with disk flexibility ignored is at 3220 RPM while the corresponding measured one is found to be 3380 RPM. When the disk flexibility is encountered in the finite element model the computed critical speed will be 3295 RPM, which is closer to the measured one than the one computed with disk flexibility ignored. This result indicates that the disk flexibility has some noticeable effect on both the computed natural frequencies and critical speeds. An analysis of the modeling error is reported in Table 2 where the superiority of including the disk flexibility in the modeling process can be easily deduced. It is also clear in Table 2 that as the rotational speed increases the modeling error significantly increases with this error kept smaller when the disk flexibility is included.

Figure 8 shows the animated two-dimensional and three-dimensional mode shapes at the first and the second critical speed. Note here that the second critical speed was theoretically computed and found to be 9986 RPM and therefore is not shown in Fig. 7 since this speed is out of range of the DC motor. The nodal point of the second mode shape is approximately at the middle point of the rotor. In the vicinity of this point it is not desired to install a disk because it will exhibit very high gyroscopic motion, which significantly maximize the deviation between forward and backward modes. Hence, significant shifts in the rotor critical speeds take place.

Finally, the critical speed map is shown in Fig. 9. This map declares how the computed critical speed would be affected by varying the average bearing stiffness. For the rotor model considered in this study, the first two critical speeds are no longer get affected by increasing the bearing stiffness beyond the value $1.1 \times 10^{8} \mathrm{~N} / \mathrm{m}$.

\section{CONCLUSIONS}

A semi-analytical finite element method has been employed to model two flexible disks attached to a flexible rotor supported by three ball bearings. A two-nodes beam element of $8-D O F$ is used to model the flexural vibrations of the flexible rotor while a four-node annular circular plate element of 8-DOF is used to model the transverse vibrations of the flexible disks. The system natural frequencies and critical speeds 
are computed in a speed rang up to a $5000 \mathrm{RPM}$. An experimental test rig has been employed to validate the theoretical findings. An acceptable matching has been found between the experimental and the simulation results. Most importantly, the results reveal that the rotor natural frequencies arid critical speeds are marginally influenced by the disk flexibility. The main result in this work is that there is a noticeable modeling error if disk flexibility is ignored in the dynamic model, and that the inclusion of disk flexibility does not entirely suppress this error but effectively reduce it. Moreover, the modeling error increases as the rotational speed increases.

\section{REFERENCES}

[1] ElBeheiry, E. M., Vibration control of randomly excited flexible rotor-bearing systems, Proc. 7th Int. Cong. Sound \& Vibr., 4-7 July, Garmisch-Partenkirchen, Germany, Vol. 1, pp 387-394, (2000).

[2] ElBeheiry, E. M., Covariance control of turbomachinery vibrations, Int. J. Acoust. Vibr., to appear in Vol. 6, No. 2. (June, 2001).

[3] Chivens, D. R. and Nelson, H. D. The natural frequencies and critical speeds of a rotating, flexible shaft-disk system, ASME J. Eng. Ind., vol. 97, No. 3, pp 881-886, (1975).

[4] Wilgen, F. J. and Schlack, JR., A. L., Effects of disk flexibility on shaft whirl stability, ASME J. Mech. Des., Vol. 101, pp 298-303, (1979).

[5] Shahab, A. A. S. and Thoms, J., Coupling effects of disk flexibility on the dynamic behavior of multi disk-shaft systems", J. Sound \& Vibr., Vol. 114, No. 3, pp 435. 452, (1987).

[6] Vance, J. M., Rotordynamics of turbomachinery, Wiley, New York, (1988).

[7] Sakata, M., Kimura, K., Park, S. K, and Ohnobe, H., Vibration of bladed flexible rotor due to gyroscopic moments, J. sound \& Vibr., Vol. 131, No. 3, pp 417-430, (1989).

[8] Kirkhope, J. and Wilson, G. J., Vibration and stress analysis of thin rotating disks using annular finite elements, J. sound \& Vibr., Vol. 44, No. 4, pp 461-474, (1976).

[9] Kirkhope, J. and Wilson, G. J., A finite element analysis for the vibration modes of a bladed disk, J. sound \& Vibr., Vol. 49, No. 4, pp 469-482, (1976).

[10] Wu, F. S. and Flowers, G. T., A transfer matrix technique for evaluating the natural frequencies and critical speeds of a rotor with multiple flexible disks, ASME J. Vibr. Acoust., Vol. 114, pp 242-248, (1992).

[11] Flowers, G. T. and Ryan, S. G., Development of a set of equations for incorporating disk flexibility in rotordynamic analyses, ASME J. Eng. Gas Turb. Pow., Vol. 115, No. 2, pp 227-233, (1993).

[12] Flowers, G. T., Modelling of an elastic disk with finite hub motions and small elastic vibrations with application to rotordynamics, ASME J. Vibr. Acoust., Vol. 118, pp 10-15, (1996).

[13] Parker, R. G., Free vibration and stability of a spinning disk-spindle system, ASME J. Vibr. Acoust., Vol. 121, pp 391-396, (1992).

[14] Lee, C.-W. and Chun, S.-B., Vibration analysis of a rotor with multiple flexible disks using assumed modes method, ASME J. Vibr. Acoust., Vol. 120, pp 87. 94, (1998).

[15] Shen, I. Y. and $\mathrm{Ku}$, C.-P. R., A nonclassical vibration analysis of a multiple rotating disk and spindle assembly, ASME J. Appl. Mech., Vol. 64, pp 165-174, (1997). 
[16] Luo, A. C. J. and Mote, Jr., C. D., Nonlinear vibration of rotating thin disks, ASME J. Vibr. Acoust., Vol. 122, pp 376-383, (2000)

[17] Reuter, F., Coupling of elastic and gyroscopic modes of rotating disk structures, Proc. 5th IFToMM Int. Conf. on Rotor Dynamics, 7-10 Sept., Darmstadt Univer. Techn., Germany, pp 443-455, (1998).

[18] Ramesh, T. C. and Ganesan, N., Finite element analysis of conical shells with a constrained viscoelastic layer, J. Sound \& Vibr., Vol. 171, pp 577-601, (1994).

[19] Kumar, D. S., Sujatina, C., and Ganesan, N., Disk flexibility effects in rotor bearing systems, Comput. \& Struct., Vol., 62, No. 4, pp 715-719, (1997).

[21] Fung, R-F. and Hsu, S-M., Dynamic formulations and energy analysis of rotating flexible-shaft/multi-flexible-disk system with eddy current brakes, ASME J. Vibr. Acoust., Vol. 122, pp 365-375, (2000).

[22] Harris, T. A., Rolling Bearing Analysis, John Wiley \& Sons, Inc., (1984).

\section{APPENDIX A}

The matrices and parameters of the rotor element are as follows [7]:

$$
\begin{gathered}
\left.\left[M_{s}\right]=\rho_{s}[R]^{T} \int_{0}^{l} S_{s}\right\}\left\{S_{s}\right\}^{T} A(z) d z[R], \quad I_{s p}=\rho_{s} \int_{b}^{l} \int_{0}^{2 \pi} \int_{1}^{r_{2}} r^{3} d r d \xi d z \\
I_{s x}=\rho_{s} \int_{0}^{d} \int_{0}^{2 \pi} f_{1}^{2} r^{2} \sin ^{2}(\Omega t+\xi) r d r d \xi d z, I_{s y}=\rho_{s} \int_{b}^{2 \pi} \int_{f_{1}^{2}}^{r_{2}} r^{2} \cos ^{2}(\Omega t+\xi) r d r d \xi d z \\
K_{s}=[R]^{T} \int E_{s} I_{s}\left[\left(\frac{d^{2}\left\{S_{s}\right\}}{d z^{2}}\right)+\left(d \frac{d^{2}\left\{S_{s}\right\}}{\partial z^{2}}\right)^{T}\right] d z[R]
\end{gathered}
$$

where $A(z)$ is the cross-sectional area of the shaft. The matrices and parameters of the annular disk element are as follows [7]:

$$
\begin{gathered}
{\left[M_{D}\right]=\pi \rho_{D}\left[B_{D}\right]^{T}\left\{\left\{S_{D}\right\}\left\{S_{D}\right\}^{T} h(r) r d r\left[B_{D}\right],\right.} \\
I_{D p}=2 \pi \rho_{D} \int_{1}^{r} r^{r} h_{D}(r) r d r, \quad I_{D x}=I_{D y}=\pi \rho_{D} \int_{1}^{r} r^{r} h_{D}(r) r d r \\
{\left[K_{D}\right]=[J 1]+\left(3-2 \mathrm{v}_{D}\right)\left[J_{2}\right]+\left(3-2 \mathrm{v}_{D}\right)\left[J_{3}\right]+2 \mathrm{v}_{D}\left[J_{4}\right]-2 \mathrm{v}_{D}\left[J_{5}\right]-2\left(3-2 \mathrm{v}_{D}\right)\left[J_{6}\right]} \\
{[J 1]=\pi D\left[B_{D}\right]^{T} \int_{1}^{r_{2}} \frac{\partial^{2}\left\{S_{D}\right\}}{\partial r^{2}} \frac{\partial^{2}\left\{S_{D}\right\}^{T}}{\partial r^{2}} h_{D}(r) r d r\left[B_{D}\right]} \\
{[J 2]=\pi D\left[B_{D}\right]^{T} \int_{1}^{2} \frac{\partial\left\{S_{D}\right\}}{\partial r} \frac{\partial\left\{S_{D}\right\}^{T}}{\partial r} h_{D}(r) \frac{1}{r} d r\left[B_{D}\right]} \\
{[J 3]=\pi D\left[B_{D}\right]^{T} \int_{1}^{2}\left\{S_{D}\right\}\left\{S_{D}\right\}^{T} h_{D}(r) \frac{1}{r^{3}} d r\left[B_{D}\right]} \\
{[J 4]=\pi D\left[B_{D}\right]^{T} f_{1}^{r_{2}} \frac{\partial^{2}\left\{S_{D}\right\}}{\partial r^{2}} \frac{\partial\left\{S_{D}\right\}^{T}}{\partial r} h_{D}(r) d r\left[B_{D}\right]}
\end{gathered}
$$




$$
\begin{aligned}
& {[J 1]=\pi D\left[B_{D}\right]^{T} f_{1}^{r} \frac{\partial^{2}}{2} \frac{\left\{S_{D}\right\}}{\partial r^{2}}\left\{S_{D}\right\}^{T} h_{D}(r) \frac{1}{r} d r\left[B_{D}\right]} \\
& {[J 1]=\pi D\left[B_{D}\right]^{T} f_{1}^{2} \frac{\partial\left\{S_{D}\right\}}{\partial r}\left\{S_{D}\right\}^{T} h_{D}(r) \frac{1}{r^{2}} d r\left[B_{D}\right]}
\end{aligned}
$$

where $D$ is the flexural rigidity of the disk. 


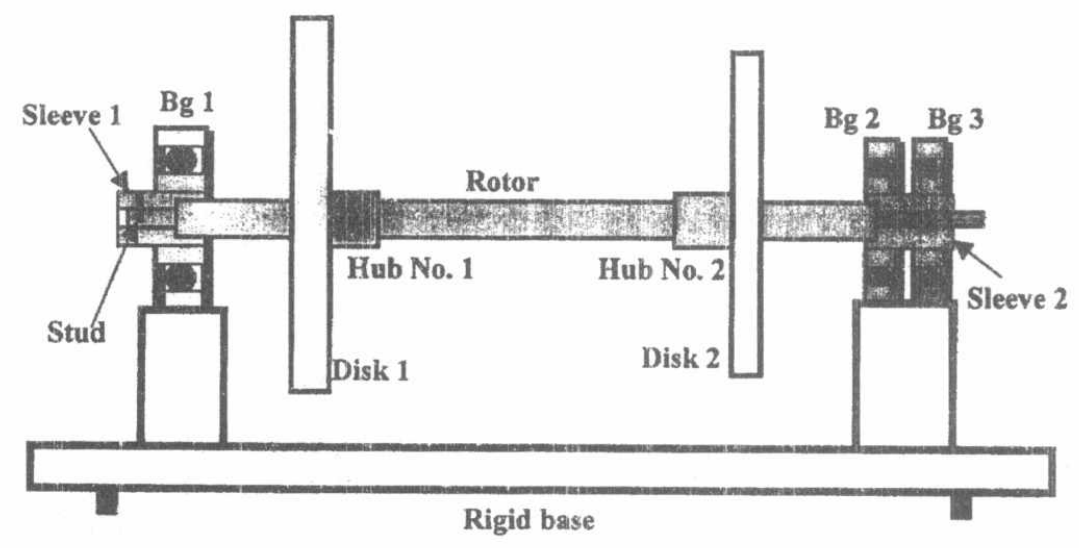

Fig. 1. Schematic diagram of the whirling apparatus with the rotor under investigation installed.

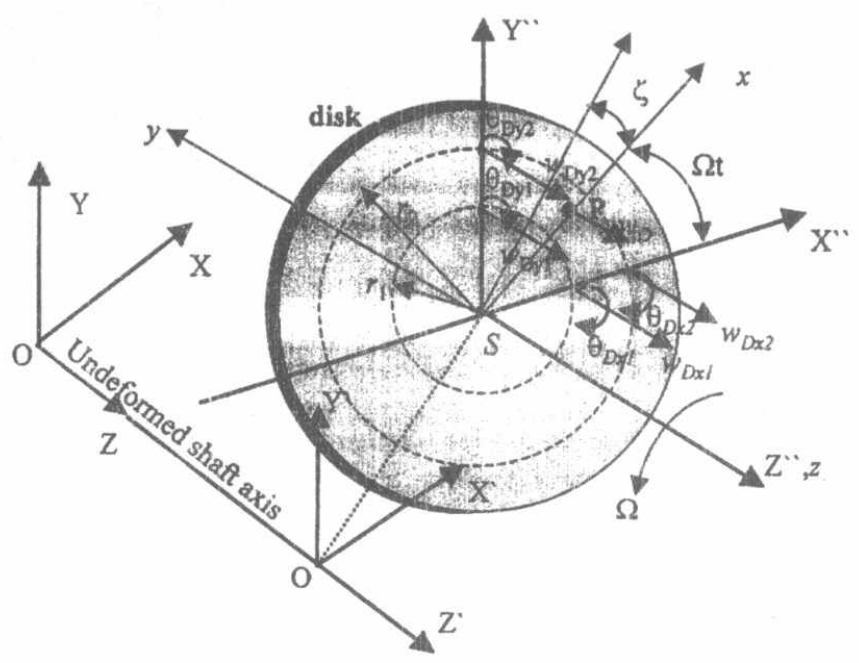

Fig. 2. Orientation of axis systems used in describing the system motion. 


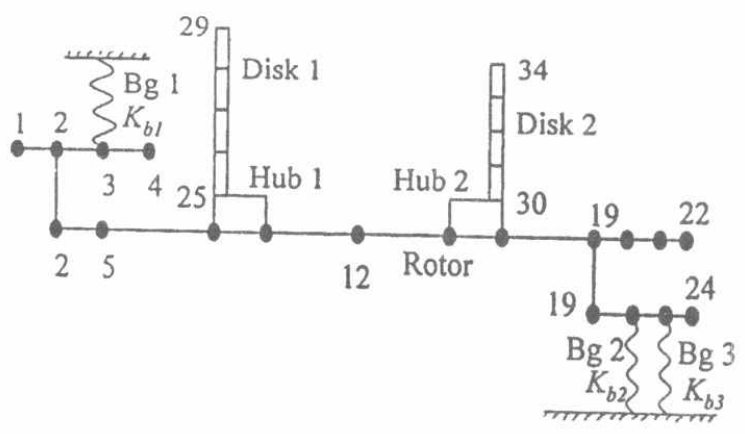

Fig. 3. Finite element representation of the whole system.

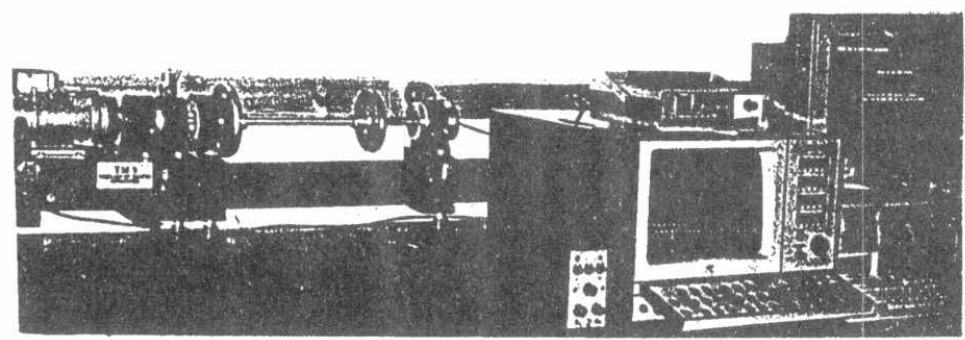

Fig. 4 Photograph of the test rig.

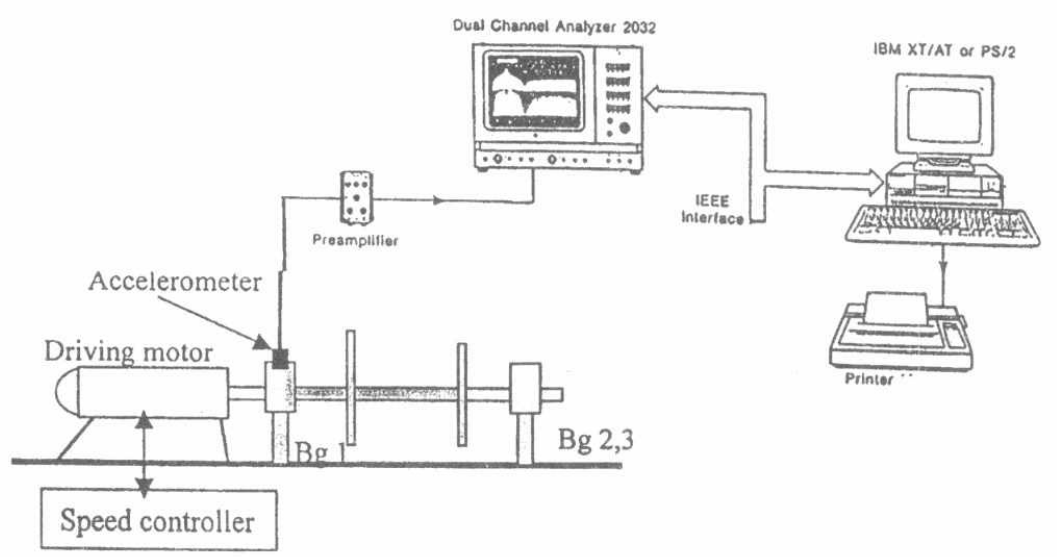

Fig. 5. Schematic diagram of the test rig and signal processing. 
Table 1. Rotor and disk element data

\begin{tabular}{|c|c|c|c|c|}
\hline \multicolumn{4}{|c|}{ Shaft element formulation } & \multirow[b]{2}{*}{ Miscellaneous } \\
\hline $\begin{array}{c}\text { Station } \\
\text { No. }\end{array}$ & $\begin{array}{c}\text { Axial } \\
\text { Distance } \\
(\mathrm{m}) \\
\end{array}$ & $\begin{array}{c}\text { Inner } \\
\text { Diameter } \\
(\mathrm{m})\end{array}$ & $\begin{array}{c}\begin{array}{c}\text { Outer } \\
\text { diameter } \\
(\mathrm{m})\end{array} \\
\end{array}$ & \\
\hline $\begin{array}{l}1 \\
2 \\
3 \\
4 \\
5 \\
6 \\
7 \\
8 \\
9 \\
10 \\
11 \\
12 \\
13 \\
14 \\
15 \\
16 \\
17 \\
18 \\
19 \\
20 \\
21 \\
22 \\
23 \\
24\end{array}$ & $\begin{array}{c}0.0 \\
0.015 \\
0.0450 \\
0.0550 \\
0.0950 \\
0.1450 \\
0.1950 \\
0.199625 \\
0.225 \\
0.245 \\
0.295 \\
0.345 \\
0.395 \\
0.445 \\
0.465 \\
0.491375 \\
0.49500 \\
0.54500 \\
0.5950 \\
0.6200 \\
0.6450 \\
0.6650 \\
0.6950 \\
0.7200\end{array}$ & $\begin{array}{c}0.017 \\
0.017 \\
0.017 \\
0 \\
0 \\
0 \\
0 \\
0 \\
0 \\
0 \\
0 \\
0 \\
0 \\
0 \\
0 \\
0 \\
0 \\
0 \\
0 \\
0 \\
0 \\
0.008 \\
0.008\end{array}$ & $\begin{array}{c}0.030 \\
0.030 \\
0.030 \\
0.010 \\
0.01425 \\
0.01425 \\
0.028 \\
0.028 \\
0.01425 \\
0.01425 \\
0.01425 \\
0.01425 \\
0.01425 \\
0.01425 \\
0.028 \\
0.028 \\
0.01425 \\
0.01425 \\
0.006 \\
0.006 \\
0.006 \\
0.020 \\
0.020\end{array}$ & $\begin{array}{l}\text { Shaft } \\
\text { Diameter }=0.01425 \mathrm{~m} \\
\text { Young's modulus }=2.07 \times 10^{11} \mathrm{~N} / \mathrm{m}^{2} \\
\text { Shear modulus }=7.83 \times 10^{10} \mathrm{n} / \mathrm{m}^{2} \\
\text { Material density }=7830 \mathrm{~kg} / \mathrm{m}^{3} \\
\text { Bearings } \\
K_{1 x}=K_{1 y}=0.8 \times 10^{7} \mathrm{~N} / \mathrm{m}^{2} \\
K_{2 x}=K_{2 y}=5.6 \times 10^{6} \mathrm{~N} / \mathrm{m} \\
K_{3 x}=K_{3 y}=4.9 \times 10^{6} \mathrm{~N} / \mathrm{m} \\
\text { Left and right sleeves } \\
\text { Young's modulus }=2.15 \times 10^{11} \mathrm{~N} / \mathrm{m}^{2} \\
\text { Shear modulus }=7.93 \times 10^{10} \mathrm{n} / \mathrm{m}^{2} \\
\text { Material density }=7930 \mathrm{~kg} / \mathrm{m}^{3} \\
\text { Left and right hubs } \\
\text { Inner diameter } 0.01425 \mathrm{~m} \\
\text { Outer diameter }=0.028 \mathrm{~m} \\
\text { Length }=0.0300 \mathrm{~m} \\
\text { Other properties are as above. }\end{array}$ \\
\hline \multicolumn{4}{|c|}{ Disk I element formulation } & Disk No.1 \\
\hline station & \multicolumn{2}{|c|}{ Inner diameter } & Outer diameter & Outer diameter $=0.01425 \mathrm{~m}$ \\
\hline $\begin{array}{l}25 \\
26 \\
27 \\
28 \\
29\end{array}$ & \multicolumn{2}{|c|}{$\begin{array}{l}0.0280 \\
0.0504 \\
0.0728 \\
0.0952 \\
0.1176\end{array}$} & $\begin{array}{l}0.0504 \\
0.0728 \\
0.0952 \\
0.1176 \\
0.1400\end{array}$ & $\begin{array}{l}\text { Young's modulus }=2.07 \times 10^{11} \mathrm{~N} / \mathrm{m}^{2} \\
\text { Shear modulus }=7.83 \times 10^{10} \mathrm{n} / \mathrm{m}^{2} \\
\text { Material density }=7830 \mathrm{~kg} / \mathrm{m}^{3} \\
\text { Disk No.2 }\end{array}$ \\
\hline $\begin{array}{l}29 \\
31 \\
32 \\
33 \\
34\end{array}$ & \multicolumn{2}{|c|}{$\begin{array}{l}0.0280 \\
0.0464 \\
0.0648 \\
0.0832 \\
0.1016\end{array}$} & $\begin{array}{l}0.0464 \\
0.0648 \\
0.0832 \\
0.1016 \\
0.1200\end{array}$ & $\begin{array}{l}\text { Outer diameter }=0.01225 \mathrm{~m} \\
\text { Young's modulus }=2.07 \times 10^{11} \mathrm{~N} / \mathrm{m}^{2} \\
\text { Shear modulus }=7.83 \times 10^{10} \mathrm{n} / \mathrm{m}^{2} \\
\text { Material density }=7830 \mathrm{~kg} / \mathrm{m}^{3}\end{array}$ \\
\hline
\end{tabular}



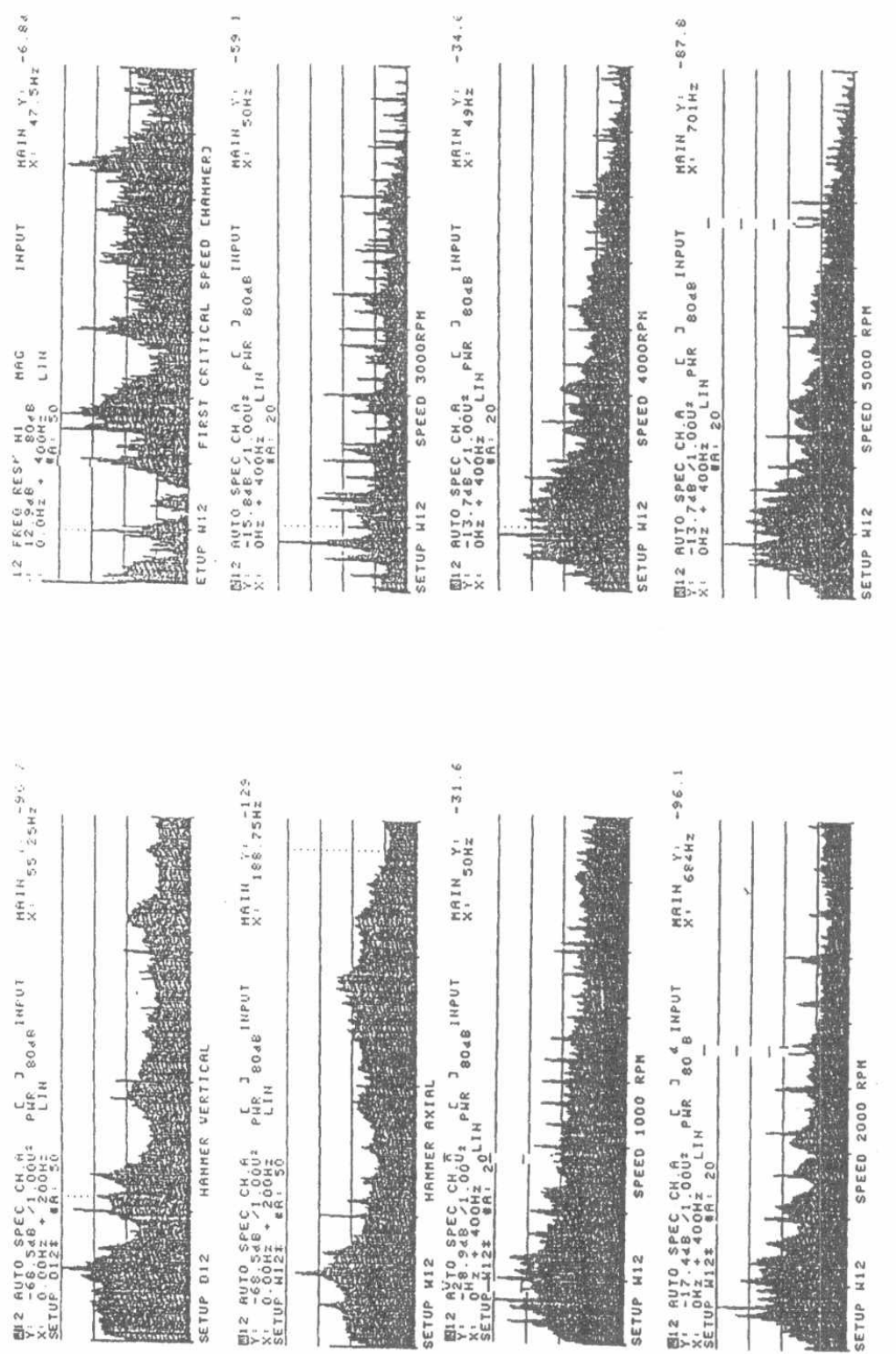


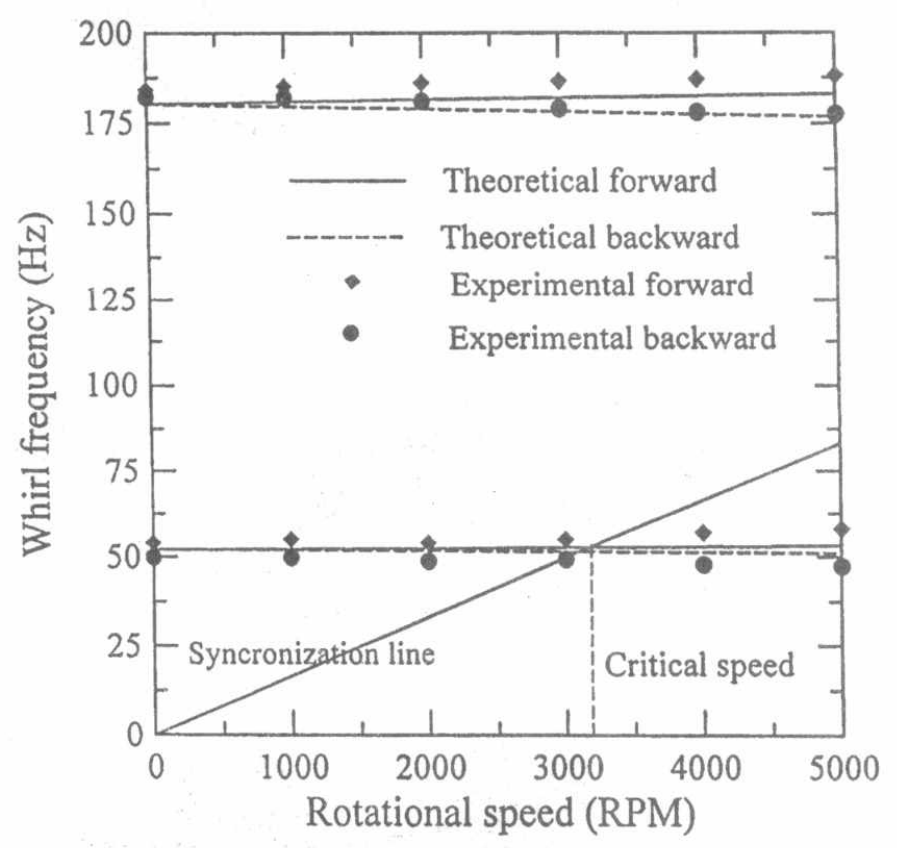

Fig. 7. Theoretical vs experimental Campbell diagram.

Table 2. Natural frequencies of the rotor model with the same disks considered as either rigid or flexible disks. The computed modeling error is in the bracket that is below each computed value with the experimental values taken as the reference ones.

\begin{tabular}{|c|c|c|c|c|c|c|c|c|}
\hline \multicolumn{3}{|c|}{ Speed $=0(R P M)$} & \multicolumn{3}{|c|}{ Speed $=3000$ (RPM) } & \multicolumn{3}{|c|}{ Speed $=5000(R P M)$} \\
\hline $\begin{array}{c}\mathrm{EX} \\
(\mathrm{rad} / \mathrm{s})\end{array}$ & $\begin{array}{l}\text { WRD } \\
(\mathrm{rad} / \mathrm{s})\end{array}$ & $\begin{array}{l}\text { WFD } \\
(\mathrm{rad} / \mathrm{s})\end{array}$ & $\begin{array}{c}\mathrm{EX} \\
(\mathrm{rad} / \mathrm{s})\end{array}$ & $\begin{array}{l}\text { WRD } \\
(\mathrm{rad} / \mathrm{s})\end{array}$ & $\begin{array}{l}\text { WFD } \\
(\mathrm{rad} / \mathrm{s})\end{array}$ & $\underset{\text { (rad/s) }}{E X}$ & $\begin{array}{l}\text { WRD } \\
(\mathrm{rad} / \mathrm{s})\end{array}$ & $\begin{array}{l}\text { WFD } \\
(\mathrm{rad} / \mathrm{s})\end{array}$ \\
\hline 345 & $\begin{array}{c}336 \\
(2.6 \%)\end{array}$ & $\begin{array}{c}336 \\
(2.6 \%) \\
\end{array}$ & 358 & $\begin{array}{c}342 \\
(4.46 \%)\end{array}$ & $\begin{array}{l}350.8 \\
(2 \%)\end{array}$ & 374.6 & $\begin{array}{c}351.5 \\
(6.16 \%)\end{array}$ & $\begin{array}{c}361.2 \\
(3.36 \%)\end{array}$ \\
\hline 1136 & $\begin{array}{l}1090 \\
(4 \%)\end{array}$ & $\begin{array}{l}1090 \\
(4 \%)\end{array}$ & 1171 & $\begin{array}{l}1110.7 \\
(5.14 \%)\end{array}$ & $\begin{array}{c}1136 \\
(2.98 \%)\end{array}$ & 1195.5 & $\begin{array}{r}1113.4 \\
(6.68 \%)\end{array}$ & $\begin{array}{c}1146.6 \\
(4 \%)\end{array}$ \\
\hline
\end{tabular}

EX: experimental value, WRD: with rigid disks, WFD: with flexible disks. 

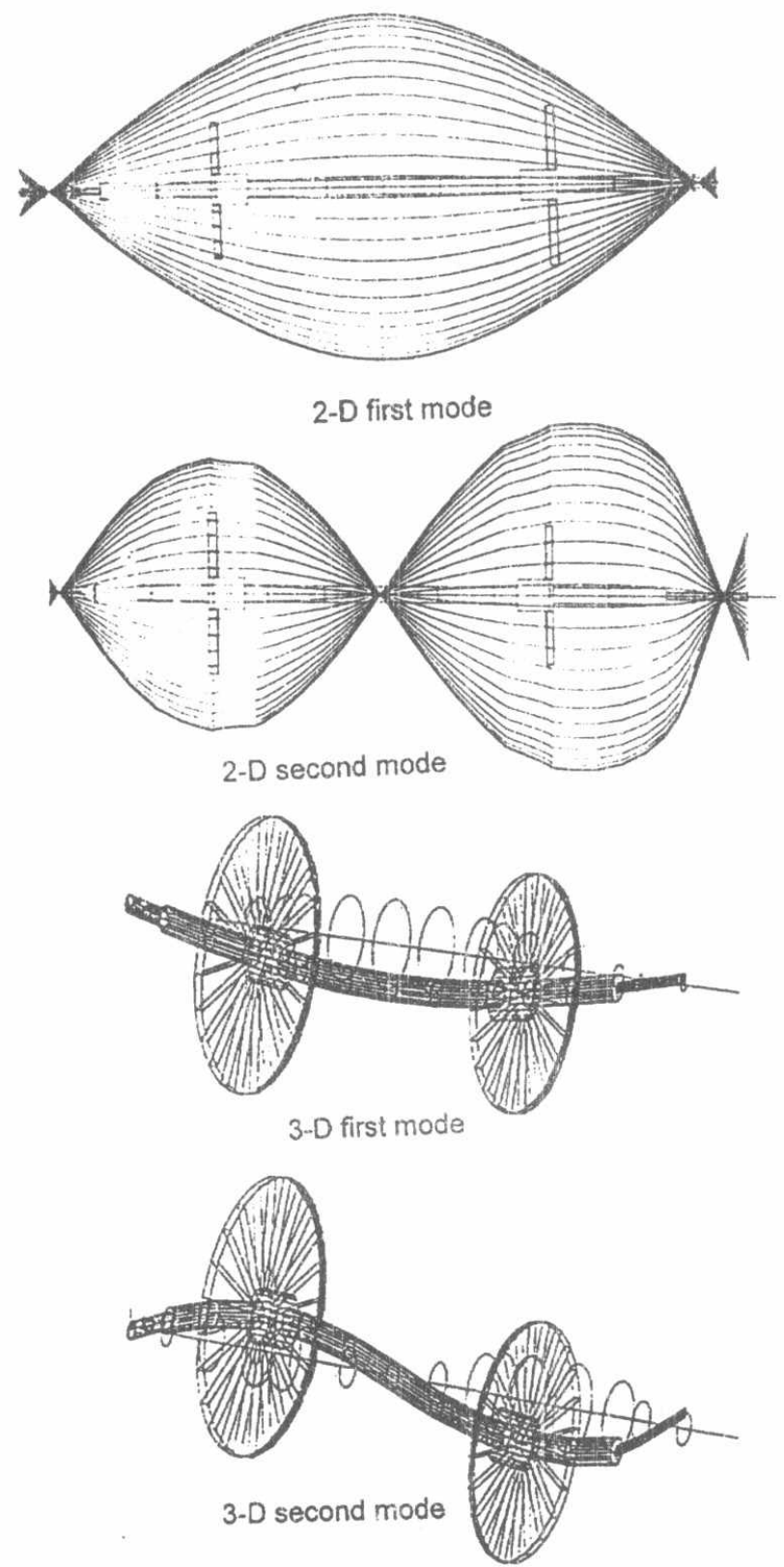

Fig. 8. Two- and Three-dimensional animated mode shapes at the first and second critical speeds. 


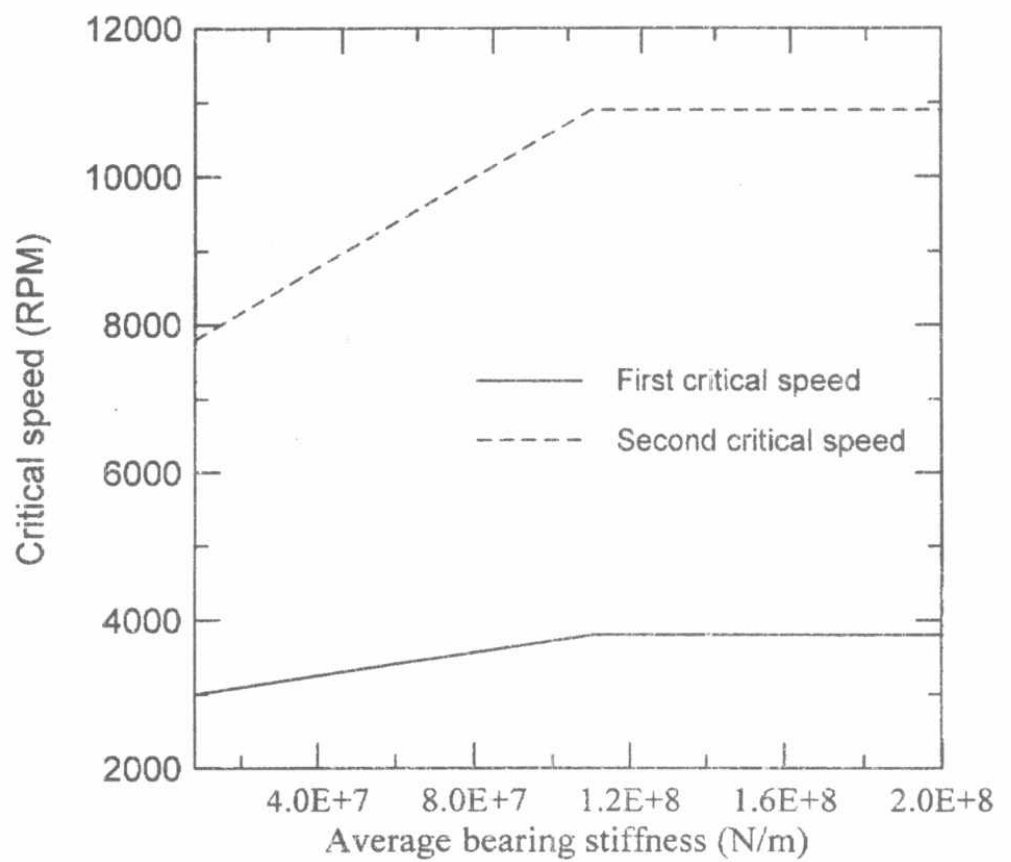

Fig. 9. Undamped critical speed map. 